\title{
PSYCHOLOGY
}

\section{THE STUDY ABOUT THE IMPACT OF EMOTIONAL TENSION ON THE STUDENTS' EXCITEMENT AND MEMORY PROCESSES}

\author{
Phd., lecturer Karamova Natavan, \\ Student Hakverdieva Zumrud, \\ Student Akbarova Khadija, \\ Student Kazenferov Eldar
}

Azerbaijan, Baku, Western Caspian University

DOI: https://doi.org/10.31435/rsglobal_ws/31082019/6644

\section{ARTICLE INFO}

Received: 20 June 2019

Accepted: 07 August 2019

Published: 31 August 2019

\section{KEYWORDS}

emotional stress,

short-term memory,

visual memory,

anxiety.

\begin{abstract}
Studies have investigated the effect of emotional stress on anxiety and memory processes. The object of the study was first-year students. Psychophysiological research methods have been used. Under the influence of emotional stress, there were changes in memory and an increase in anxiety levels.
\end{abstract}

Citation: Karamova Natavan, Hakverdieva Zumrud, Akbarova Khadija, Kazenferov Eldar. (2019) The Study About the Impact of Emotional Tension on the Students' Excitement and Memory Processes. World Science. 8(48), Vol.3. doi: 10.31435/rsglobal_ws/31082019/6644

Copyright: () 2019 Karamova Natavan, Hakverdieva Zumrud, Akbarova Khadija, Kazenferov Eldar. This is an open-access article distributed under the terms of the Creative Commons Attribution License (CC BY). The use, distribution or reproduction in other forums is permitted, provided the original author(s) or licensor are credited and that the original publication in this journal is cited, in accordance with accepted academic practice. No use, distribution or reproduction is permitted which does not comply with these terms.

Introduction. In modern times, there is high need for human's development as person. There are several key criteria for evaluating personality: social productivity, emotional stress tolerance, creativity, enjoy special status in society etc. All the criteria are involved in the human's full development and are considered as important for the evaluation of developmental level $(2,4,5,7)$. From literary sources, it is known that long-term and frequent emotional reactions lead to the formation of persistent irritation in brain, and this is the basis of psycho-emotional stress. As a result, excessive tension of adaptive mechanisms occurs, subsequently resulting in serious changes in endocrine system, metabolism, functions of cardiovascular system, and so on. Of course, given the fact that modern human lives in chronic psychoemotional stress, it is clear that the organism is exposed to permanent risk factors for pathological processes $(1,3,6,7)$. Exam stress is a classic example of stress and plays an important role in students' achieving success in their studies. There is much information about the number of psychological changes in students being caused by emotional tension. One of the most exciting points is the reaction of excitement and memory processes to emotional tension $(2,3,8)$. Three types of excitement are of the most importance in the learning process: situational, individual, general excitement. The peculiarities of modern living conditions, the rapid development of intellectual programs, the transition to student life, the increasing importance of information create growing demands in young organisms $(3,7)$. However, many aspects of mental and psycho-emotional stress 
have not been studied sufficiently. One of the pathological risk factors in the mental state of the student is the changes that occur in the personal and situational excitement levels $(2,3)$.

The memory process, which is of paramount importance in cognitive processes, is the ability of the living organism to encode, store and retrieve information about events that have affected it before. Memory is closely related to training and emotional tension. Short-term memory, which is the type of memory, determines the importance of the incoming information in the body. If this information is important for the body, especially in meeting its essential needs, then it is processed in the intermediate memory and goes into long-term memory. Otherwise, it is quickly forgotten. Throughout our life the short-term memory is the major stage (initial platform) for main life-saving habits, all gained behavior and activities in being transferred to the constant memory. It is determined that the volume of short-term memory in humans is equal to $7 \pm 2$ units (3).

The visual memory is a form of memory in which the image, the shape and the trace of the external environment is captured for storage for some 50-500 ms. For example: a visual image is captured during an eye blink. To store the image of the external environment in the memory differs individually and it depends mostly on the functional state of the subject, in particular its emotional and motivational impressions, upbringing, professional background, age and other individual factors. A direct indicator, trace of the external environment is practically inappropriate. Initially it is the first stage of processing the information acquired from external environmental impacts. It is known that the information in the external environment is extreme and they are multi-channeled, in other words, associated with vision, hearing, defending, tactile effects, and the most of these are the effects of visionary perceptions (2).The organism chooses the most important of these general information for itself, according to its needs. The information with emotional effect falls more quickly into the visual memory and the visual impairment can be formed for a number of reasons, so that the emotional tension factor is the key among these factors.

To define the effects of emotional tension on excitement and memory processes, it was aimed to conduct psycho physiological studies on I year students and to identify these relationships. The cycle of colloquium, which takes place during semester was taken as a model of emotional tension. The studies were conducted in 3 stages: during the normal learning day (20-25 days prior to colloquium), 15 minutes before the colloquium and in post colloquium stage. The objects of the study were 28 students of I year of the faculty of psychology. The studies Spielberg and Khanin's test methods were applied for testing the level of situational and individual excitement, "Number Memory" tests to determine the short-term memory and the "Imagery memory" to determine the level of visual memory whereas and the data obtained was processed statistically.

Research results. During the ordinary lesson day, it was observed that even the ordinary testing process was approached by the students with sense of responsibility. This conclusion is made based on the following findings; situational excitement was $40 \pm 3,23$ points, individual excitement $55 \pm$ 4,25 points, short-term $5,78 \pm 1,76$ and the visual memory increase up to $8,1 \pm 2,48$ points (Picture 1 ). Where as the retesting prior to colloquium showed an increase in the figures; situational excitement was $49 \pm 3,71$ points, individual excitement $60 \pm 2,75$ points, as for the cognitive indicators, short-term $6,58 \pm 1,84$ and the visual memory $10,5 \pm 1,56$ points (Picture 2 ). The post colloquium testing indicated sudden and interesting results; situational excitement was $23 \pm 1,49$ points, individual excitement $42 \pm$

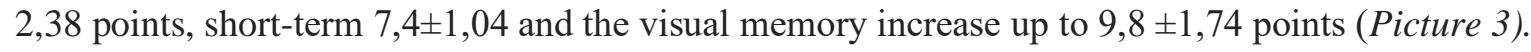

\section{w situational excitement $\mathbf{m}$ individual excitement}

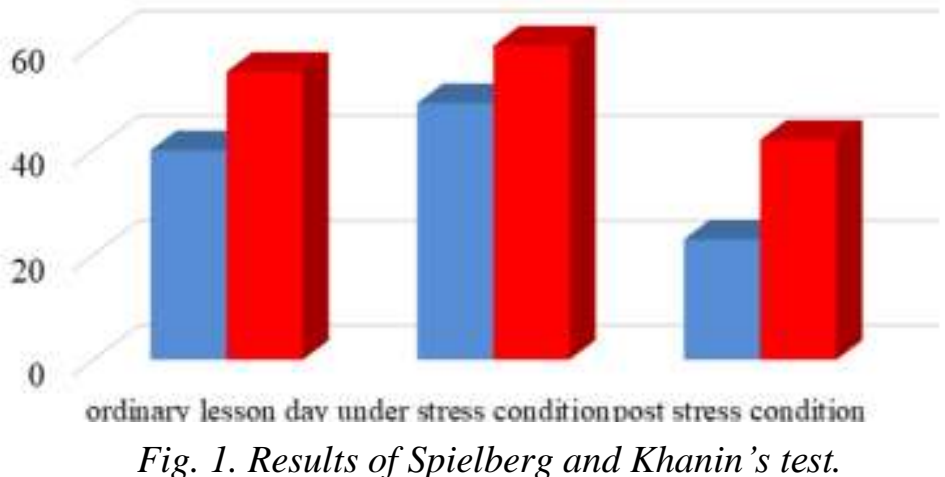




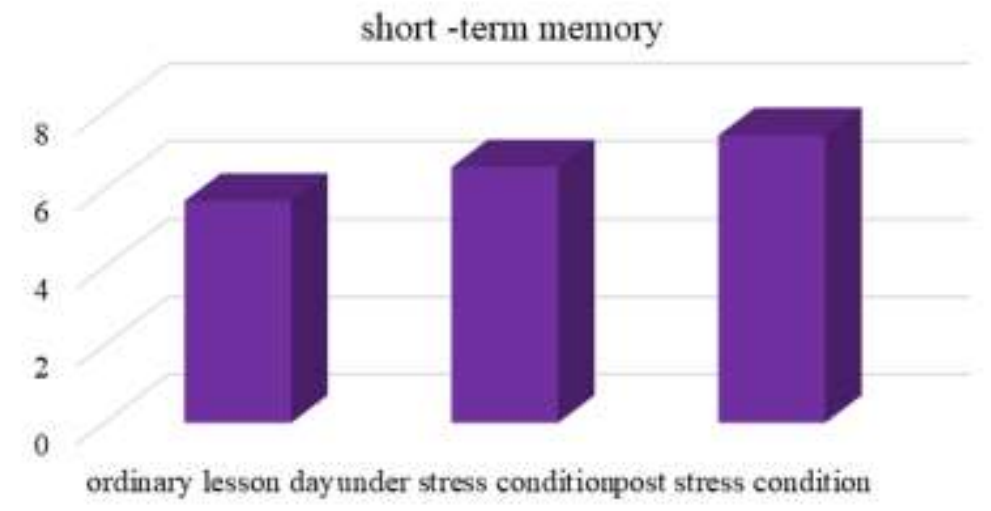

Fig. 2. Effect of emotional stress on short-term memory.

Thus, during the analysis of the results, it's been found out that both the situational and the individual excitement were at higher level on the ordinary learning day. This can be attributed to the fact that for the first time the testing process had a stress affect, and the level of excitement was high as the result of the students' responsive approach to the process. A very high level of situational and individual excitement was observed during the test before the colloquium. This can be explained by the fact that the colloquium process, which plays the role of stress effectiveness, is very important for students; they have had a higher sense of responsibility for the stage of tests and preparation for the exam and have applied the maximum approach for gaining success. The very high level of excitement during the testing proves once again the activation of cognitive-comprehension processes too. The level of excitement increases as the sense of responsibility increases. Interesting facts were obtained in the after exam findings. So that the students' admiration of the two levels of excitement was observed due to the fact that these students are aware of the elimination of the stress factor and the tension in the understanding processes.

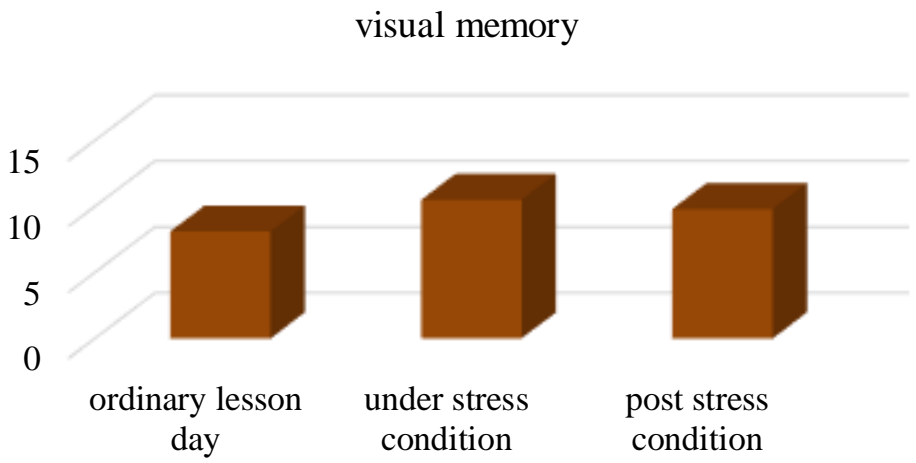

Fig. 3. Effect of emotional stress on visual memory.

Thus, the analysis of the obtained results proved the process of colloquium creating emotional tension that caused an increased situational and individual excitability as well as activation of cognitive processes.

A comparative analysis of the cognitive findings revealed that students' short-term memory on the ordinary learning day was lower than normal. This allows the testing to be thought of as being approached with a sense of responsibility and the testing process to be a source of emotional tension. The results obtained in the state of emotional tension prove that acquaintance with the testing process and at the same time the cognitive processes are activated under the influence of emotional tension. Naturally, the activation of the common understanding processes also affects the success indicator and results in achieving success. As for the post colloquium state, the short-term memory was higher than normal and showed an understanding of the elimination of the process that caused the emotional tension.

The results obtained during the visual memory study revealed interesting facts. So that, the results obtained in all three cases had shown that students have had high visual memory. Even though the precolloquium rate has risen significantly as a result of the effects of emotional tension, it has still been found to be at a higher level than during a normal learning day, despite a slight decline after the test. This proves the positive effect of the stress factor on the visual memory and on increasing of its activation. 
Hence, the state of emotional tension can affect visual and short-term memory by weakening it, at the same time increasing the sense of responsibility, and eventually promoting cognitive processes and increasing the indicator of success. One of the interesting points in the literature is that depending on the physiological age categories, the emotional tension triggers psycho physiological changes of different levels $(2,7)$. According to the studies conducted on students studying in different courses the psycho physiological changes were higher in students who were enrolled in the I-II course than in the third year under the influence of neuro-emotional stress, which could be explained by the adaptation of the students to the teaching process (3). However, in some sources, fourth-year students are highlighting an increase in the level of emotional tension, which is explained by the fact that they are in their final year of education and that the final exams would play a decisive role in their future life $(3,8)$. It is noted that the level of emotional tension is higher in the pre-exam period, at which the psycho-physiological changes are marked at higher levels as a result of the weakening of the intersystem relationships. In post-exam studies, the body's high functional tension is noted and the incidence is comparatively lower than during the pre-exam period $(2,3)$.

The exam process is viewed as a stress-maker, complex, requiring adaption and need for good marks in order to achieve the goals, affecting self-esteem, and the strong revealer of "The self-concept" (9). As for the marks achieved in the exam, it will have a different effect on the nervous system, mental state, mental activity, motivation, and on personality formation in general. Low level of life experience in of most young people and lack of fully formed operative thinking abilities in states of emotional tension often causes psychological stress. The term "psychological stress" was included in the literature by R.Lazarus (10). According to the scholar, responses originated under the effects of psychological stress could be considered as a threat to defense processes. One of the important factors in the emergence of psychological stress is the increased level of excitement. Under the influence of psychological stress, achieving success becomes a challenge. Of course, the success of the educational process should be influenced by a number of factors: personal-psychological relationships and the type of higher nervous system $(11,12)$, motivation and the level of personality development (13), educational motivation (14), self-esteem and the degree of self-confidence (15), the excitement being at optimal level (3) The increase in the level of excitement under the influence of mental stress is of particular importance. Among the mental states, more attention has been paid to studying excitement (2). It is known that among the psycho-physiological changes the level of excitement is more evident during the exam process, which is a cause for psycho-emotional stress. Increasing of both individual and situational types of excitement during exams is one of the major factors that prevent the successful completion of it. Excitement is a state of feeling of emotional discomfort, which is associated with the sense of danger and unpleasant predictions. Although the feeling of fear is a response to a specific hazard, the feeling of excitement is the realization of uncertain feelings against the real danger. As for the feeling of excitement, it is an individual psychological trait and is characterized by a tendency toward anxiety and often occurs when it comes to the feeling of excitement and can be regarded as a condition of transition to excitement. Of course, the incensement of the level of these processes can adversely affect the learning process $(3,11,14)$. At the same time, high excitement can also lead to activation of cognitive processes.

Emotion affects the level of memory processes. Emotion is the first warning alert: the memory captures emotionally sensitive events together with its details and is activated when a certain critical situation occurs. Emotion regulates behavior by influencing emotion, memory, and focus. During the emotional assessment of conditions, the circumstances of more importance, containing potential hazards and that could be valued as fearful are kept in focus. Emotion may end an ongoing cognitive task resolution process and based on the existing condition may generate a fulfillment of new requirements $(1,6)$. Emotion can play the role of a seductive factor: pleasant and unpleasant emotions can determine the behavioral manners and the activation of the human memory. Emotion has got an important role in the development of psycho-emotional stress, which can't go aside without affecting the memory processes.

Psycho-emotional stress plays an important role in the formation of a number of heart diseases and the diseases in nervous system during adolescence and youth. Almost the majority of schoolchildren and students are experiencing emotional stress while sitting for exams. But after 20 minutes of the exam, the indicators were back to normal (3). Psycho-physiological studies on 1st year students have proven once more that emotional tension affects excitement and cognitive processes. To reduce emotional stress and to achieve success, conducting preventive conversations with students and creating similar situations to the exam may have a positive impact on reaching the high educational goals. 


\section{REFERENCES}

1. Калмыкова Е. М. Этнопсихологические особенности самоактуализации личности студентов: дисс. Канд. Психол. наук: Моск., 2008. 233 с.

2. Карамова Н.Я. Влияние эмоционального напряжения на формирование когнитивных процессов у школьников в зависимости от уровня их умственного развития. Информационно-аналитический журнал «Актуальные проблемы современной науки», №4, том 48, Москва, 2009, стр. 274-278.

3. Карамова Н.Я., Мамедов З.Г. Особенности влияния эмоционального напряжения на когнитивные процессы у подростков в зависимости от исходного уровня умственного развития. «Естественные науки», Вестник МОГУ, №1, 2011, ст.22-25.

4. Bayliss D.M., Jarrold C., Gunn D.M., Baddeley A.D. The complexities of complex span: explaining individual differences in working memory in children and adults // Journal Exp. Psychol. Gen., 2003, V.132, p.71-92.

5. Bishop S. J. The cognitive processing of emotional information in childhood anxiety, depression and posttraumatic stress disorder // Journal of Child Psychology and Psychiatry, 2001, V.41, p. 513-523

6. Kugelmass S., Marcus J., D’Esposito M. From cognitive to neuronal models of working memory // Philos.Trans. R. Soc. Lond. B. Biol. Sci., 2007, v.362, №1481, p.761

7. Rothbaum, B. O., Ruchkin D.S., Grafman J., Cameron K. Working memory retention systems: a state of activated long-term memory // Behav. Brain. Sci. 2003, V. 26, №6, p.709

8. Zeller A., Handschin D., Gyr N., Martina B., Battergay E. Blood pressure and heart rate of students undergoing a medical licensing examination // Blood Press, 2004, V. 13, № 1, p. 20-24

9. Burns, R. B. Self-Concept Development and Education. Holt, Rinehart \& Winston.1982, p.441

10. Lazarus R.S. Cognitive and coping processes in emotion / Stress and coping. New York.: Columbia Univ. press, 1977, p.144-157

11. Merlin V.S. "Lectures on the psychology of motives." - Perm, 1970, p. 120.

12. Rubinstein S.L. "Being and consciousness" monograph, 1960.

13. Izard C.E. The structure and functions of emotions: implications of cognition, motivation and personality // The G. Stanley Hall Lectures Series / Ed. Cohen I.S. Washington: Amer. Psychol. Assoc., 1989, V.9, p. 35-73

14. Sanders A.F. Towards a model of stress human performance // Acta Psychologica, 1983, V.53, p.61-68

15. Wong P. T. Effective management of life stress: The resource-congruence model // Stress medicine, 1999, V. 9, p. 51-60 